\title{
PEMBUATAN RECYCLE PLASTIK HDPE SEDERHANA MENJADI ASBAK
}

\author{
Anis Masyruroh ${ }^{1}$, Iroh Rahmawati ${ }^{2}$ \\ ${ }^{1,2}$ Teknik Sipil, Universitas Banten Jaya, Jl. Syech Nawawi Albantani Serang Banten \\ Email: anismasyruroh@unbaja.ac.id
}

\begin{abstract}
Plastic is a commodity that is often used in everyday life. Almost all equipment or products, especially household appliances used are made of plastic and are often used as packaging for raw materials. Plastic waste is an environmental problem on a global scale because plastic takes a long time to be recycled. The types of plastics are PET (Polyethylene Terephtalate), HDPE (High Density Polyethylene), $V$ (PlyvinylChloride), LDPE (Low Density Polyethylene), PP (Polypropylene), PS (Polytyrene), and OTHER. Plastic waste has a bad impact on the environment because of the nature of plastic which is difficult to decompose naturally by the soil, even though it has been buried for hundreds of years. The purpose of this community service activity is to recycle HDPE plastic waste into an ashtray. This is done because of the large piles of plastic waste that are increasingly unsettling, causing disease, reducing soil fertility, and damaging ecosystems on land and in the oceans. Activities carried out by collecting HDPE type plastic waste from the community around the village of Sijaga, then cleaned of dirt, dried and cut into pieces then heated then printed. After the HDPE plastic recycle became an ashtray, the results were uneven and there was still empty space in the printed results. The use of color in making recycles is very influential to make the appearance of plastic more attractive.
\end{abstract}

Keywords: Garbage; Plastic; Ashtray; Environment.

\begin{abstract}
ABSTRAK
Plastik adalah salah satu komoditi yang sering digunakan dalam kehidupan sehari-hari. Hampir semua peralatan atau produk khususnya peralatan rumah tangga yang digunakan terbuat dari plastik dan sering digunakan sebagai pengemas bahan baku. Sampah plastik menjadi masalah lingkungan berskala global karena plastik membutuhkan waktu yang cukup lama dalam proses daur ulang. Adapun jenis-jenis plastik yaitu PET (Polyethylene Terephtalate), HDPE (High Density Polyethylene), V (PlyvinylChloride), LDPE (Low Density Polyethylene), PP (Polypropylene), PS (Polytyrene), dan OTHER. Sampah plastik berdampak buruk bagi lingkungan karena sifat plastik yang memang susah diuraikan oleh tanah secara alamiah, meskipun sudah tertimbun beratus tahun lamanya. Tujuan dari kegiatan pengabdian kepada masyarakat ini adalah daur ulang recycle sampah plastik HDPE menjadi asbak. Hal ini dilakukan karena banyaknya tumpukan sampah plastik yang semakin meresahkan, menimbulkan penyakit, berkurangmya kesuburan tanah, dan merusak ekosistem di darat maupun di lautan. Kegiatan dilakukan dengan cara mengumpukan sampah plastic jenis HDPE dari masyarakat sekitar desa sijaga, kemudian dibersihkan dari kotoran, keringkan dan dipotong-potong kemudian dilakukan pemanasan kemudian dicetak. Setelah dilakukan pengabdian recycle plastik HDPE menjadi asbak didapatkan hasil yang tidak rata dan masih terdapat ruang kosong pada hasil cetakan. Penggunaan warna dalam pembuatan recycle sangat berpengaruh untuk membuat penampilan plastik lebih menarik.
\end{abstract}

Kata Kunci: Banten; Pelatihan; Kayu; KOTAKU; PUPR.

\section{PENDAHULUAN}

Indonesia merupakan salah satu negara berkembang yang memiliki populasi penduduk terbesar nomer 3 di dunia. Dengan menyandang gelar tersebut maka Indonesia beresiko menampung masalah yang sering di hadapi manusia, yaitu sampah. Dengan pertumbahan 
penduduk yang terus menerus bertambah maka produktifitas sampah juga akan semakin meningkat. Masalah terbesar yang di hadapi Indonesia adalah bagaimana cara menangani dan meminimalisir sampah yang tidak dapat tertampung dengan tepat. Selain itu juga masalah sampah ini begitu banyak menimbulkan masalah untuk semua kalangan dan kurangnya kesadaran masyarakat akan sampah ini juga sangat berpengaruh akan terjadinya masalah tersebut.

Produksi sampah nasional menunjukkan tren yang terus meningkat seiring dengan terjadinya pertumbuhan ekonomi dan peningkatan jumlah penduduk. Salah satu jenis sampah yang menjadi perhatian adalah sampah plastik. Kontribusi sampah plastik terhadap total produksi sampah nasional mencapai $15 \%$ dengan pertumbuhan rata-rata mencapai $14,7 \%$ per tahun dan menempatkan sampah plastik sebagai kontributor terbesar kedua setelah sampah organik (Kholidah dkk, 2018; Dokhikhah dkk, 2015; Trihadiningrum dkk, 2006). Studi di berbagai kota Indonesia menunjukkan kontribusi sampah plastik terhadap total sampah kota di Indonesia bervariasi antara lain Jakarta (14\%), Surabaya (10,8\%), Palangkaraya (15\%) (Dokhikhah dkk, 2015; Aprilia dkk, 2012; Permana dkk, 2010).

Persoalan sampah bukan lagi sekedar masalah kebersihan dan lingkungan saja, akan tetapi sudah menjadi persoalan sosial yang berpotensi menimbulkan konflik. Hampir semua kota besar di Indonesia belum memiliki sistem penanganan sampah yang baik (Damanhuri, 2005). Semua kota di Indonesia memiliki manajemen sampah yang sama yaitu menggunakan metode kumpul-angkut-buang. Merupakan metode manajemen persampahan yang masih klasik yang akhirnya berubah menjadi praktek pembuangan sampah secara sembarangan tanpa mengikuti ketentuan teknis di lokasi yang sudah ditentukan.

Berdasarkan Undang-undang No 18 Tahun 2008 dan Peraturan Pemerintah No 81 Tahun 2012 tentang pengelolaan sampah di lakukan dengan dua fokus utama yaitu pengurangan dan penanganan sampah. Pengurangan sampah seperti yang di jelaskan di dalam Undang-undang maupun Peraturan Pemerintah dilakukan mulai dari sumber sampah sampai pada pengelolaan akhir. Pengurangan sampah diwujudkan dengan melibatkan masyarakat maupun pihak pengelola sampah. Pengurangan sampah sendiri di lakukan dengan proses 3R ( Reuse, Recycle dan Reduce). Hingga saat ini metode pengolahan sampah 3R ( Reuse, Recycle dan Reduce) dianggap metode yang paling sesuai dalam mengurangi sampah di kota maupun wilayah, karena mampu mengurangi timbulan sampah sebesar 15-20 \% (Nurhayati, 2013). Sedangkan untuk penanganan sampah merupakan hal teknis dalam mengelolah sampah mulai dari pewadahan, pengumpulan, pengangkutan, sampai pada pemrosesan akhir.

Kedua fokus pengelolaan sampah baik itu pengurangan maupun penanganan sampah merupakan amanat dari Undang-Undang` pengelolaan sampah di Indonesia sehingga untuk di 
tindak lanjuti dengan Perda pengelolaan sampah di setiap daerah dan juga digunakan sebagai metode dalam pengelolaan sampah setiap kota, wilayah maupun kawasan.

Setiap aktifitas manusia secara pribadi maupun kelompok, dirumah, kantor, pasar, sekolah, maupun dimana saja akan menghasilkan sampah, baik sampah organik maupun sampah anorganik. Dalam Undang-Undang Nomor 18 tahun 2008 pasal 1 tentang sampah disebutkan bahwa sisa kegiatan sehari-hari manusia dan/atau proses alam yang berbentuk padat atau semi padat berupa zat organik atau anorganik yang memiliki sifat mudah terurai atau tidak dapat terurai yang dianggap sudah tidak berguna lagi dan dibuang kelingkungan. Plastik merupakan material terbuat dari nafta yang merupakan produk turunan minyak bumi yang diperoleh melalui proses penyulingan. Karakteristik plastik yang memiliki ikatan kimia yang sangat kuat sehingga banyak material yang dipakai oleh masyarakat berasal dari plastik. Namun plastik merupakan material yang tidak bisa terdekomposisi secara alami (non biodegradable) sehingga setelah digunakan, material yang berbahan baku plastik akan menjadi sampah yang sulit diuraikan oleh mikroba tanah dan akan mencemari lingkungan (Jatmiko dkk, 2018).

Pengelolaan sampah plastik menjadi masalah sebab plastik merupakan material yang tidak bisa terdekomposisi secara alami (non biodegradable) sehingga pengelolaan sampah plastik dengan landfill maupun open dumping tidak tepat dilakukan. Salah satu alternatif penanganan sampah plastik adalah dengan melakukan proses daur ulang (recycle). Sampah plastik adalah sampah yang dapat di daur ulang. Pemanfaatanya bisa sebagai campuran aspal, energy listrik, ataupun diolah kembali menjadi bahan baku plastik. Sampah plastik memiliki berbagai jenis yang dikategorikan berdasarkan komponen penyusunnya seperti HDPE (High Density Polyethylene), LDPE (Low Density Polyethylene), PETE/PET (Polyethylene Terephthalate), V atau PVC (Polyvinyl Chloride), PP (Polypropylene), PS (Polystyrene), dan lain-lain (Other).

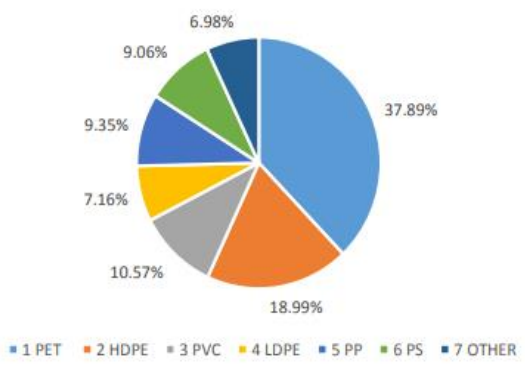

Gambar 1. Komposisi Sampah Plastik

Dari ke tujuh jenis sampah plastic HDPE dan LDPE memiliki potensi penyebab kekumuhan yang paling besar kedua, karenakan HDPE dan LDPE merupakan plastic yang paling banyak sekali dimanfaatkan untuk botol susu, botol shampo, botol sabun cair, kantong 
plastik, botol kosmetik, kursi lipat, jerigen, botol pelumas (oli), botol obat, dan botol minuman. Hal ini disebabkan oleh sifat dari HDPE dan LDPE yang tahan panas dan tahan terhadap bahan kimia sehingga HDPE dan LDPE memiliki aplikasi yang sangat luas (Nurminah,2002)

Daur ulang adalah proses pengolahan kembali barang-barang yang sudah tidak memiliki nilai ekonomis, melalui proses fisik maupun kimiawi atau keduanya, sehingga diperoleh produk yang dapat dimanfaatkan dan dapat diperjualbelikan lagi. Daur ulang (recycle) sampah plastik dapat dibedakan menjadi empat cara yaitu daur ulang primer, daur ulang sekunder, daur ulang tersier dan daur ulang quarter. Pertama yaitu, daur ulang primer merupakan daur ulang limbah plastik menjadi produk yang memiliki kualitas yang hampir sama dengan produk aslinya. Daur ulang ini dapat dilakukan pada sampah plastik yang bersih, yang tidak tercampur dengan bahan atau material lain dan terdiri dari satu jenis plastik. Kedua yaitu daur ulang sekunder merupakan daur ulang yang menghasilkan produk yang sejenis dengan produk aslinya tetapi untuk kualitas berada dibawahnya. Ketiga yaitu, daur ulang tersier merupakan daur ulang sampah plastik menjadi bahan kimia atau menjadi bahan bakar. Terakhir daur ulang quarter adalah proses untuk mendapatkan energi yang terkandung di dalam sampah plastik (Kumar dkk., 2011 dalam Surono, 2013).

HDPE (High-Density Polyethylene) adalah salah satu tipe dan jenis plastik yang biasa dipakai pada botol susu yang berwarna putih, wadah makanan, galon air minum, botol diterjen, botol lotion, kursi lipat, dan lain-lain. Plastik jenis HDPE merupakan salah satu bahan plastik yang aman untuk digunakan manusia, karena memiliki kemampuan untuk mencegah reaksi kimia antara kemasan plastik berbahan HDPE dengan makanan atau minuman yang dikemasnya dan plastik HDPE juga memiliki 3 sifat bahan yang lebih kuat, keras, buram serta tahan terhadap suhu tinggi. Untuk jenis plastik HDPE (High-Density Polyethylene) umumnya pada bagian bawah kemasan botol plastik tertera logo daur ulang dengan angka 2 ditengahnya, serta tulisan HDPE dibawah segitiga

Berdasarkan jenis produknya, terdapat 6 jenis plastik yaitu Polyethylene Terephthalate (PET), High Density Polyethylene (HDPE), Polyvinyl Chloride (PVC), Low Density Polyethylene (LDPE), Polypropylene (PP), Polystyrene (PS) dan Other. (Hartulistiyoso, dkk, 2014). Umumnya sampah plastik memiliki komposisi 46\% Polyethylene (HDPE dan LDPE), 16\% Polypropylene (PP), 16\% Polystyrene (PS), 7\% Polyvinyl Chloride (PVC), 5\% Polyethylene Trephthalate (PET), 5\% Acrylonitrile-Butadiene-Styrene (ABS) dan polimerpolimer lainnya. Lebih dari $70 \%$ plastik yang dihasilkan saat ini adalah Polyethylene (PE), Polpropylene (PP), Polystyrene (PS), dan Polyvinyl Chloride (PVC) sehingga sebagian besar studi yang dilakukan berhubungan dengan keempat jenis polimer tersebut (Praputri dkk, 2016). 


\begin{tabular}{|c|c|c|}
\hline Ko & $\begin{array}{l}\text { Tipe } \\
\text { Plastik }\end{array}$ & $\begin{array}{c}\text { Beberapa } \\
\text { penggunaan plastik }\end{array}$ \\
\hline & $\begin{array}{l}\text { PET } \\
\text { atau } \\
\text { PETE }\end{array}$ & $\begin{array}{l}\text { Botol minuman ringan } \\
\text { dan air mineral, bahan } \\
\text { pengisi kantong tidur } \\
\text { dan serat tekstil }\end{array}$ \\
\hline & HDPE & $\begin{array}{l}\text { Kantong belanja, } \\
\text { kantong freezer, botol } \\
\text { susu dan krim, botol } \\
\text { sampo dan pembersih }\end{array}$ \\
\hline & $\begin{array}{l}\text { PVC } \\
\text { atau V }\end{array}$ & $\begin{array}{l}\text { Botol juice, kotak } \\
\text { pupuk, pipa saluran }\end{array}$ \\
\hline & LDPE & $\begin{array}{l}\text { Kotak ice cream, } \\
\text { kantong sampah, } \\
\text { lembar plastik hitam }\end{array}$ \\
\hline & $\mathbf{P P}$ & $\begin{array}{l}\begin{array}{l}\text { Kotak ice cream, } \\
\text { kantong } \\
\text { goreng, sedotan, kotak } \\
\text { makanan }\end{array} \\
\text { mentang }\end{array}$ \\
\hline$P$ & PS & $\begin{array}{l}\text { Kotak yoghurt, plastik } \\
\text { meja, cangkir } \\
\text { minuman panas, } \\
\text { wadah makanan siap } \\
\text { saji, baki kemasan }\end{array}$ \\
\hline $\mathrm{IHIE}$ & OTHER & $\begin{array}{l}\text { Botol minum olahraga, } \\
\text { acrylic dan nylon }\end{array}$ \\
\hline
\end{tabular}

Gambar 2. Karakteristik Jenis Plastik

Karakteristik Jenis Plastik Kode Tipe Plastik Beberapa penggunaan plastik PET atau PETE Botol minuman ringan dan air mineral, bahan pengisi kantong tidur dan serat tekstil HDPE Kantong belanja, kantong freezer, botol susu dan krim, botol sampo dan pembersih PVC atau V Botol juice, kotak pupuk, pipa saluran LDPE kotak ice cream, kantong sampah, lembar plastik hitam PP Kotak ice cream, kantong kentang goreng, sedotan, kotak makanan PS Kotak yoghurt, plastik meja, cangkir minuman panas, wadah makanan siap saji, baki kemasan OTHER Botol minum olahraga, acrylic dan nylon.

Berdasarkan asalnya, sampah plastik dapat digolongkan menjadi sampah plastik industri dan sampah plastik rumah tangga. Sampah plastik industri berasal dari industri pembuatan plastik maupun industri yang bergerak di bidang pemrosesan. Sampah plastik rumah tangga dihasilkan terkait dengan aktivitas manusia sehari-hari misalnya plastik kemasan, plastik tempat makanan atau minuman (Syamsiro dkk, 2013). Berdasarkan sifatnya, plastik dapat dibedakan menjadi dua macam yaitu thermoplastic dan thermosetting. Thermoplastic adalah bahan plastik yang bila digunakan untuk membuat material tertentu dapat didaur ulang dan dibuat menjadi bentuk material yang lain melalui proses pemanasan. Contoh thermoplastic antara lain yaitu Polyethylene, Polypropylene, Nylon, Polycarbonate. Thermosetting adalah plastik yang jika telah dibuat dalam material tertentu, tidak dapat dicairkan untuk didaur ulang 
atau dibuat produk lain. Contoh plastik yang termasuk thermosetting antara lain Phenol formaldehyde, Urea Formaldehyde, Melamine Formaldehyde (Das \& Pandey, 2007; Surono, 2013).

Senyawa yang paling sederhana melalui proses thermal (pemanasan/pembakaran) dengan atau tanpa maupun sedikit oksigen. Pirolisis merupakan proses endotermis artinya proses pirolisis hanya bisa terjadi ketika dalam sistem diberikan energi panas. Energi panas yang dibutuhkan dalam proses ini bersumber dari tenaga listrik maupun berasal dari tungku pembakaran dengan bahan bakar berupa limbah kayu seperti potongan-potongan kayu, serbuk gergaji, dan lain-lain. Istilah lain dari pirolisis adalah "destructive distillation" atau destilasi kering, merupakan proses penguraian yang tidak teratur dari bahan-bahan organik yang disebabkan oleh adanya pemanasan tanpa berhubungan dengan udara luar. Plastik yang mengalami proses pirolisis akan terdekomposisi menjadi material-material pada fase cair dalam bentuk minyak bakar, fase gas berupa campuran gas yang dapat terkondensasi maupun tidak dapat terkondensasi dan fase padat berupa residu maupun tar (Hamidi dkk, 2013). Dibandingkan dengan bio-fuel seperti biodisel maupun bioetanol, minyak hasil pirolisis plastik memiliki beberapa kelebihan. Minyak hasil pirolisis tidak mengandung air sehingga nilai kalorinya lebih besar. Selain itu, minyak hasil pirolisis tidak mengandung oksigen sehingga tidak menyebabkan korosi (Hidayah \& Syafrudin, 2018).

Berdasarkan latar belakang yang telah diuraikan diatas, maka penulis tertarik untuk melaukan kegiatan pengabdian kepada masyarakat, tentang inovasi mengenai pemanfaatan limbah sampah untuk membantu dalam pengelolahan lingkungan yaitu "recycle HDPE".

\section{METODE}

Jenis kegiatan pengabdian ini menggunakan metode eksperimental, merupakan upaya untuk pemanfaatan sampah plastic khususnya HDPE menjadi lebih ekonomis, dengan cara didaur ulang menjadi asbak, dengan menggunakan metode pemanasan. Lokasi penelitian dilakukan di Desa Sijaga Kota Serang, untuk bahan baku atau sampel plastic HDPE diambil dari pemulung dan pengepul yang berada di kota Serang.

Recycle plastik HDPE ini dilakukan karena banyaknya tumpukan sampah plastik yang semakin meresahkan, menimbulkan penyakit, berkurangmya kesuburan $\mathrm{t}$ anah, dan merusak ekosistem di darat maupun di lautan. Tahapan pembuatan recycle platik HDPE sebagai berikut:

1. Tahapan persiapan Persiapan bahan meliputi kegiatan pengadaan bahan yang akan digunakan dalam penelitian. Bahan-bahan yang digunakan dalam penelitian ini antara lain agregat kasar, agregat halus, plastik HDPE . Agregat kasar dan halus didapatkan dari toko material PD, sedangkan untuk plastik HDPE dari pemulung dan pengepul di desa sijaga. 
2. Plastik HDPE 100 gr dibersihkan dari kotoran kemudian dikeringkan.

3. Pemotongan yang merupakan tahapan pembuatan sampah kemasan plastik menjadi potongan-potongan kecil. Proses ini bertujuan untuk menyamarkan label produk, gambar, serta tulisan yang terdapat pada kemasan plastik sehingga produk yang dihasilkan tidak terlihat sebagai produk daur ulang dari sampah kemasan plastik.

4. Pengujian bahan Bahan-bahan yang digunakan dalam penelitian ini terdiri dari agregat kasar, agregat halus, plastik HDPE yang terlebih dahulu dilakukan pengujian sesuai dengan metode pengujian yang digunakan. Adapun untuk pengujian plastik HDPE meliputi berat jenis, suhu, dan kehilangan berat.

5. Pemanasan dan pelunakan didalam kaleng bekas roti selama 12 menit, dilakukan pada potongan-potongan sampah kemasan plastik hasil dari proses pemotongan menggunakan gunting. Tahapan ini bertujuan merekatkan potongan-potongan sampah kemasan plastik menjadi bentuk lembaran sehingga memudahkan pengaplikasian material tersebut di prosesproses selanjutnya,

6. Pembentukan dan pencetakan, dimana proses pembentukan dilakukan dengan cara olehkan minyak goreng pada kaleng cetakan yaitu 2 kaleng bekas minuman yang berbeda ukuran.

7. Berdasarkan SNI 03-0691-1996 berikut dijelaskan mengenai prosedur pengujian kuat tekan, yaitu : a. Mengambil contoh uji 10 buah yang sudah berbentuk kubus. b. Menekan contoh uji hingga hancur dengan mesin penekan.

8. Penghitungan kuat tekan dihitung dengan rumus : Kuat Tekan $=\mathrm{P}$ L Keterangan $: \mathrm{P}=$ Beban Tekan $(\mathrm{N}) \mathrm{L}=$ Luas Bidang Tekan (mm2) Kuat tekan rata-rata diambil dari jumlah kuat tekan dibagi jumlah contoh uji.

9. Plastik yang telah melebur dituangkan kedalam dalam cetakan dan diberi tekanan menggunakan kaleng yang lebih kecil untuk membentuk plastik.

10. Plastik yang telah dicetak di dinginkan selama 8 menit hingga plastik memadat.

11. Setelah memadat plastik dilepakan dari cetakan dan plastik dirapikan dari plastik yang melebihi dari ukuran cetakan menggunakan gunting. Plastik diamplas untuk membuat permukaan lebih halus dan rapih.

12. Penghalusan atau proses finishing merupakan proses terakhir yang dilakukan setelah melalui proses-proses sebelumnya. 


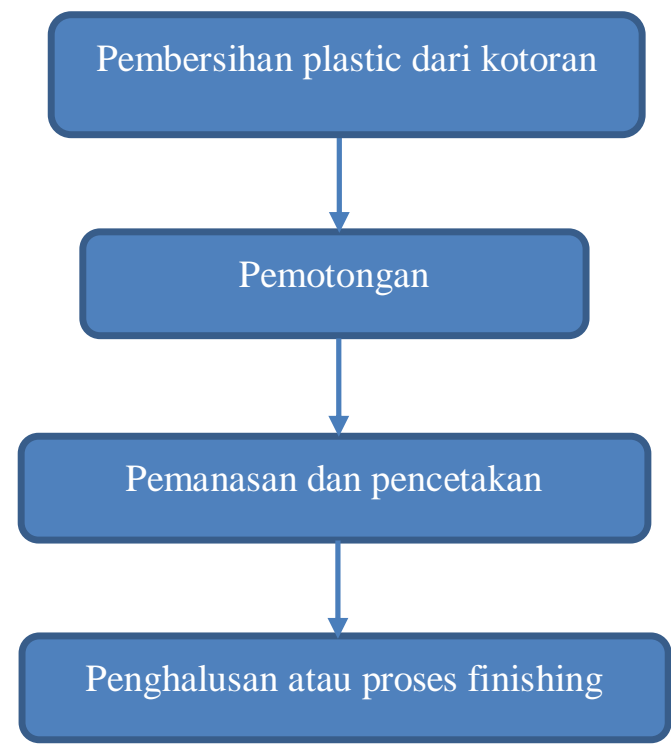

\section{Bagan 1. Tahapan Pembuatan Asbak Plastik}

Pada proses finishing, dilakukan pelapisan clear spray agar material hasil daur ulang terlihat rapi dan mengkilap. Secara umum semua proses dalam metode recycle dilakukan menggunakan peralatan sederhana yang mudah diperoleh seperti gunting, alat pertukangan, kaleng roti dan sebagainya. Produk yang dihasilkan dari pengolahan limbah plastik dengan menggunakan metode recycle dapat diaplikasikan pada berbagai kerajinan kreatif yang mempunyai nilai seni dan nilai ekonomi yang tinggi.

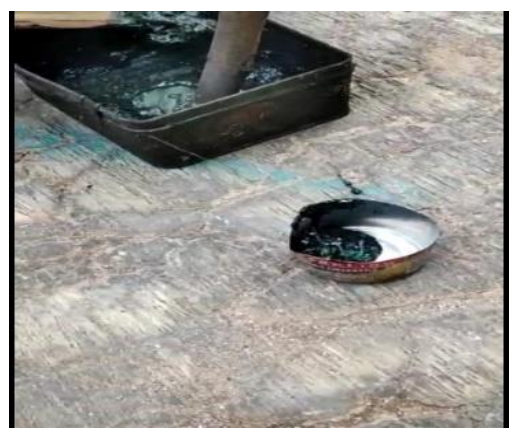

\section{Gambar 3. Proses Pencetakan Plastik}

\section{HASIL DAN PEMBAHASAN}

Meskipun sampah plastik mempunyai dampak negatif yang cukup besar tetapi di satu sisi penemuan plastik ini mempunyai dampak positif, karena plastik memiliki keunggulankeunggulan dibandingkan dengan material lain. .Dampak negatif yang ditimbulkan oleh sampah plastic selain dapat mengurangi kesuburan tanah maka jika dibuang sembarangan dapat menyumbat saluran drainase, selokan dan sungai sehingga dapat menyebabkan banjir. Apabila 
sampah plastic dibakar maka dapat mengeluarkan zat-zat yang berbahaya bagi kesehatan manusia (Pramiati, 2016).

Plastik HDPE merupakan salah satu bahan terbaik untuk manufaktur. Kekuatan ,kepadatan bahan, serta kemudahannya untuk dibentuk membuatnya populer dalam beragam jenis industri. Dan bisa digunakan untuk membuat kontainer, kemasan, pipa, dan bahan konstruksi yang awet dan tidak mudah rusak. (Anonim,2020). Jenis ini berlogo segitiga bernomor 2 biasanya ada dalam botol kemasan produk-produk olahan susu. Ciri HDPE yakni keras hingga semifleksibel, tahan bahan kimia dan kelembaban, permeabel terhadap gas, permukaan berlilin (waxy), buram (opaque), mudah diwarnai, diproses dan dibentuk. (mia,2013) Penelitian ini menitik beratkan dan memilih sampah plastik jenis HDPE sebagai bahan dasar pembuatan asbak plastik dikerenakan sampah plastik jenis ini yang banyak ditemukan ditempat pemilahan sampah, para pemilah tingkat bawah atau pemulung banyak mengumpulkan sampah HDPE ini karna harga jual lebih mahal dari jenis sampah plastic yang lain. Dan juga jenis ini yang mempunyai karkteristik yang paling bagus untuk dijadikan asbak plastic terutama untuk asbak plastic, mebel atau furniture.

HDPE (High Density PolyEthylene) biasa dipakai untuk botol kosmestik, botol obat, botol minuman, botol susu yang berwarna putih susu, tupperware, galon air minum, kursi lipat, jerigen, dan pelumas. Memiliki sifat bahan yang lebih kuat, keras, buram dan lebih tahan terhadap suhu tinggi. HDPE direkomendasikan hanya untuk sekali pakai, karena pelepasan senyawa SbO3(Antimon Trioksid a) terus meningkat seiring waktu.

Recycel plastik HDPE merupakan suatu proses daur ulang dalam menanggulangi penumpukan sampah plastik. Limbah plastik HDPE dapat digunakan kembali setelah didaur ulang dan dimanfaatkan menjadi asbak yang banyak digunakan disetiap rumah untuk tempat abu rokok. Prinsip kerja dalam membuat daur ulang sampah plastik menjadi asbak yaitu dengan menggunakan panas dan tekanan. Berbeda dengan pembuatan daur ulang yang telah menggunakan mesin hotpres yang menfaatkan tenaga listrik untuk menghasilkan daya panas. Keunggulan dari daur ulang plastik HDPE ini dapat dibuat sendiri tanpa membutuhkan biaya yang mahal, adapun sumber pemanasan recycle ini menggunakan api untuk meleburkan plastik.

Hasil pengujian recycle plastik HDPE masih didapatkan hasil yang tidak rata dan masih terdapat ruang kosong pada hasil cetakan. Akan tetapi hal tersebut diakibatkan dari pencetakan yang tipis sehingga tidak efektif untuk digunakan sebagai pencetakan. Plastik yang panas dan diberikan tekanan yang menyebabkan kaleng bekas menjadi pecah sehingga permukan plastik tidak rata dan terdapat ruang kosong pada plastik.

Penggunakan plastik yang memiliki banyak varian warna akan membuat tampilan plastik lebih menarik hasil dari perpaduan warna yang dihasilkan. Untuk membuat permukaan 
yang datar dan teratur perlu digunakan pisau untuk memotong permukaan yang berlebih dari cetakan kemudian dihaluskan menggunakan amplas. Penghalusan ini berguna untuk membuat permukaan datar dan menyesuaikan bentuk yang diinginkan yaitu asbak

Sampah plastik HDPE ini dikumpulkan dari masyarakat Lingkungan Desa Sijaga Kota Serang dengan penduduk $125 \mathrm{KK}$. Apabila setiap rumah mengunakan asbak daur ulang ini maka akan mengurangi jumlah sampah plastik sebesar 12,5 kg plastik HDPE. Setiap produksi satu asbak daur ulang ini dapat mengurangi plastik HDPE sebesar 100.

Produksi daur ulang ini dalam jumlah besar mampu mengurangi sampah plastik HDPE di Lingkungan Desa Sijaga Kota Serang. Dengan berkurangnya penumpukan sampah dapat membantu membuat tempat Desa Sijaga menjadi lebih bersih, terhindar dari tempat yang kumuh. Lingkungan yang sehat membuat masyarakatnya dapat terhindar dari berbagai penyakit yang berasal dari sampah seperti diare dan tetanus.

Asbak daur ulang ini bisa menjadi alternatif lain dalam mengurangi sampah plastik yang bertebaran di Lingkungan Desa Sijaga. Pembuatan daur ulang dengan menambahkan keterampilan atau seni dalam penampilan asbak ini dapat menarik perhatian masyarakat terutama generasi melenial yang selalu menggunakan media sosial dalam mengepresikan dirinya. Dengan menarik perhatian generasi melenial ini mampu menjadi peluang usaha bagi masyarakat terutama masyarakat Lingkungan Desa Sijaga. Peranan media sosial ini mampu menjadi ladang promosi yang tak berbayar dan dapat menarik perhatian banyak orang. Produksi ini dapat menjadi usaha baru serta mampu mengurangi dari timbulan sampah plastik.

\section{KESIMPULAN}

Berbagai upaya dilakukan untuk penanggulangan sampah plastic, cara ini sangat penting mengingat sampah plastic sebagai salah satu penyumbang kerusakan alam. Metode recycle salah satu cara penanggulangan sampah plasik sebagai solusi untuk mencegah kerusakan pada lingkungan. Kesimpulan dari kegiatan pengabdian kepada masyarakat pembuatan recycle plastik HDPE sebagai berikut:

1. Penggunaan warna-warni plastik dalam pembuatan recycle sangat berpengaruh untuk membuat penampilan asbak plastik lebih menarik.

2. Pencetakan yang bersifat keras akan mempermudah saat pencetakan serta terhindanya dari cacar bentuk.

3. Hasil pengujian recycle plastik HDPE masih didapatkan hasil yang tidak rata dan masih terdapat ruang kosong pada hasil cetakan diakibatkan dari pencetakan yang tipis sehingga tidak efektif untuk digunakan sebagai pencetakan. Plastik yang panas dan diberikan tekanan 
yang menyebabkan kaleng bekas menjadi pecah sehingga permukan plastik tidak rata dan terdapat ruang kosong pada plastik.

\section{DAFTAR PUSTAKA}

Damanhuri., Enri \& Padmi, T. (2015). Pengelolaan Sampah Terpadu Edisi Pertama. Bandung: Program Studi Teknik Lingkungan Fakultas Teknik Sipil dan Lingkungan Institut Teknologi Bandung.

Das, S \& Pandey, S. (2007). Pyrolysis and Catalytic Cracking of Municipal Plastic Waste for Recovery of Gasoline Range Hydrocarbons. Theses. National Institute of Technology Rourkela.

Hidayah, N \& Syafrudin. (2018). A Review on Landfill Management in the Utilization of Plastic Waste as an Alternative Fuel. Proceeding The 2nd International Conference on Energy, Environmental and Information System (ICENIS 2017). Semarang: Universitas Diponegoro 15-16 Agustus 2017.

Hamidi, et al. (2013). Pyrolysis of Household Plastic Wastes. British Journal of Applied Science \& Technology, 3(3), 417-439.

Jatmiko, Hermain \& Arieyanti. (2018). Pemanfaatan Limbah Plastik Sebagai Bahan Baku Pembuatan Bahan Bakar Alternatif. Jurnal Litbang Vol. XIV, No.1. Hal 58-67.

Kumar S., Panda, A. K., \& Singh, R.K. (2011). A Review on Tertiary Recycling of HighDensity Polyethylene to Fuel, Resources, Conservation and Recycling Vol. 55 893- 910. Nurhayati, N. (2013). Penerapan Prinsip 3R dalam Pengelolaan Sampah sebagai Upaya Pengendalian Pencemaran Lingkungan di Kabupaten. Bantul: Universitas Atmajaya Jogyakarta.

Praputri, et al. (2016). Pengolahan Limbah Plastik Polypropylene Sebagai Bahan Bakar Minyak (BBM) dengan Proses Pyrolysis. Seminar Nasional Teknik Kimia-Teknologi Oleo Petro Kimia Indonesia. Pekanbaru.

Syamsiro, et al. (2013). Fuel Oil Production from Municipal Plastic Wastes in Sequential Pyrolysis and Catalytic Reforming Reactors. Energy Procedia, 47, 180 - 188.

Undang-Undang Nomor 18 Tahun 2008 tentang Pengelolaan Sampah Rumah Tangga dan Sampah Sejenis Sampah Rumah Tangga. 